\title{
Microbial colonization induces dynamic temporal and spatial patterns of NF-KB activation in the zebrafish digestive tract
}

\author{
Michelle Kanther ${ }^{1,2}$, Xiaolun Sun ${ }^{3}$, Marcus Mühlbauer ${ }^{3}$, Lantz C. Mackey ${ }^{1}$, Edward J. Flynn \\ III $^{1}$, Michel Bagnat ${ }^{4}$, Christian Jobin ${ }^{3,5,6}$, and John F. Rawls ${ }^{1,6}$ \\ ${ }^{1}$ Department of Cell and Molecular Physiology, University of North Carolina, Chapel Hill, NC \\ ${ }^{2}$ Curriculum in Genetics and Molecular Biology, University of North Carolina, Chapel Hill, NC \\ ${ }^{3}$ Department of Medicine, University of North Carolina, Chapel Hill, NC \\ ${ }^{4}$ Department of Cell Biology, Duke University Medical School, Durham, NC \\ ${ }^{5}$ Department of Pharmacology, University of North Carolina, Chapel Hill, NC \\ ${ }^{6}$ Department of Microbiology and Immunology, University of North Carolina, Chapel Hill, NC
}

\begin{abstract}
Background \& Aims-The nuclear factor $\kappa$-light-chain enhancer of activated B cells (NF- $\kappa \mathrm{B}$ ) transcription factor pathway is activated in response to diverse microbial stimuli to regulate expression of genes involved in immune responses and tissue homeostasis. However, the temporal and spatial activation of NF- $\mathrm{KB}$ in response to microbial signals have not been determined in whole living organisms, and the molecular and cellular details of these responses are not well understood. We used in vivo imaging and molecular approaches to analyze NF- $\kappa \mathrm{B}$ activation in response to the commensal microbiota in transparent gnotobiotic zebrafish.
\end{abstract}

\begin{abstract}
Methods-We used DNA microarrays, in situ hybridization, and quantitative reverse transcription PCR analyses to study the effects of the commensal microbiota on gene expression in gnotobiotic zebrafish. Zebrafish PAC2 and ZFL cells were used to study the NF- $\mathrm{KB}$ signaling pathway in response to bacterial stimuli. We generated transgenic zebrafish that express enhanced green fluorescent protein under transcriptional control of NF- $\mathrm{kB}$, and used them to study patterns of NF- $\kappa \mathrm{B}$ activation during development and microbial colonization.
\end{abstract}

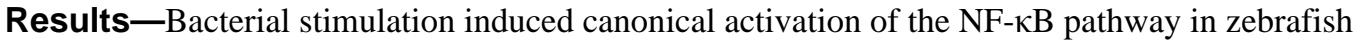
cells. Colonization of germ-free transgenic zebrafish with a commensal microbiota activated NF$\kappa \mathrm{B}$ and led to up-regulation of its target genes in intestinal and extra-intestinal tissues of the

\footnotetext{
(C) 2011 The American Gastroenterological Association. Published by Elsevier Inc. All rights reserved.

Correspondence: Christian Jobin, Ph.D., Dept. of Medicine, Pharmacology, University of North Carolina, Chapel Hill, NC 27599 USA, Phone: +1-919-966-7884, Fax: +1-919-966-7468, job@med.unc.edu, John F. Rawls, Ph.D., Dept. of Cell and Molecular Physiology, University of North Carolina, Chapel Hill, NC 27599 USA, Phone: +1-919-966-8340, Fax: +1-919-966-6927, jfrawls@med.unc.edu.

Financial Disclosure: The authors declare that they do not have competing financial interests.

Transcript Profiling: NCBI Gene Expression Omnibus accession number GSE16857

Author Contributions: study concept and design (MK, XS, MM, CJ, JFR); acquisition, analysis and interpretation of data (MK, XS, MM, LCM, EJF, MB, JFR); drafting of the manuscript (MK, CJ, JFR); critical revision of the manuscript for important intellectual content (MK, XS, MM, MB, CJ, JFR); obtained funding (MB, CJ, JFR); study supervision (CJ, JFR).

Publisher's Disclaimer: This is a PDF file of an unedited manuscript that has been accepted for publication. As a service to our customers we are providing this early version of the manuscript. The manuscript will undergo copyediting, typesetting, and review of the resulting proof before it is published in its final citable form. Please note that during the production process errors may be discovered which could affect the content, and all legal disclaimers that apply to the journal pertain.
} 
digestive tract. Colonization with the bacterium Pseudomonas aeruginosa was sufficient to

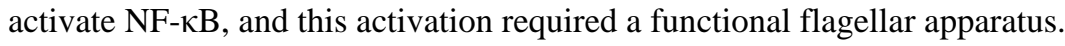

Conclusions-In zebrafish, transcriptional activity of NF- $\mathrm{KB}$ is spatially and temporally regulated by specific microbial factors. The observed patterns of NF- $\mathrm{kB}-\mathrm{dependent} \mathrm{responses} \mathrm{to}$ microbial colonization indicate that cells in the gastrointestinal tract respond robustly to the microbial environment.

\section{Keywords}

EGFP; acute phase protein; axenic; Myd88

\section{INTRODUCTION}

The microbiota residing within the adult human gastrointestinal tract consists of $\sim 1000$ species of Bacteria as well as members of Archaea, Eukarya, and virus. The collective genomes of these microbial residents encode $>3$ million genes, vastly outnumbering the genes encoded by our own genome ${ }^{1}$. The microbiota impacts numerous host biological processes such as development and edification of the mucosal immune system, metabolism of dietary nutrients, and intestinal epithelial cell proliferation and differentiation ${ }^{1-3}$. An important concept in host-microbe interaction is the presence of conserved innate sensors that provide a sophisticated communication network between microorganisms and their eukaryotic hosts. For example, Toll-like receptors (TLRs) can specifically recognize components of bacterial cell walls, nucleic acids, or locomotion systems such as flagella ${ }^{4}$. Once engaged by microbial ligands, TLRs and their adapter proteins such as Myd88 propagate their signals to a complex network of intracellular effector systems including mitogen activated protein kinase (MAPK; p38, Erk, SAPK/JNK), interferon responsive factor (IRF) 3 and nuclear factor kappa-light-chain-enhancer of activated B cells (NF- $\mathrm{KB}$ ) signal transduction 5,6 .

Among the various effector systems utilized by TLRs, the NF- $\kappa B$ transcriptional regulatory pathway has attracted much attention for its role in innate and adaptive responses, inflammation, proliferation, and cellular differentiation. Although TLR functions have been largely analyzed in the context of pathogenic microbial infections, recent evidence has revealed that the TLR/NF- $\kappa \mathrm{B}$ signaling axis also promotes protective function in the intestine ${ }^{7}$. These protective functions are especially apparent during injury responses to radiation, ischemia or chemical-induced damage, and are mostly attributed to NF- $\mathrm{\kappa B}$ signaling within intestinal epithelial cells (IECs) ${ }^{8-15}$. Transgenic NF $-\kappa B$ reporter mice have revealed that NF- $\mathrm{KB}$ is activated in diverse organs during development and biological stresses ${ }^{16-19}$ However, whether different types of microbial factors elicit a similar or differential pattern of NF- $\mathrm{BB}$ responses in the whole body is currently unknown. In addition, the relationship between microbial colonization of the intestine and NF- $\mathrm{kB}$ host responses in gastrointestinal and non-GI tissues remains unresolved.

The zebrafish (Danio rerio) has unique features that make it an attractive model organism to study interactions between microorganisms and whole-body NF- $\mathrm{kB}$ response and function. First, zebrafish are transparent through early adulthood, allowing in vivo time-lapse microscopy of host and microbial cells. Second, the zebrafish digestive tract is similar to that of mammals, possessing a liver, gall bladder, pancreas, and intestine. The zebrafish intestinal epithelium is comprised of cell types present in other vertebrates, including absorptive enterocytes and secretory goblet cells and enteroendocrine cells ${ }^{20,21}$. The development of the zebrafish digestive tract is rapid, reaching a stage that supports feeding and digestion by 5 days post-fertilization (dpf). Third, methods have been developed for 
producing germ -free (GF) zebrafish and for colonizing them with selected microbes ${ }^{22}$. Finally, the zebrafish is protected by humoral and cell -mediated immune systems that are highly homologous to those of mammals ${ }^{23,24}$. The zebrafish genome encodes components of the NF- $\kappa \mathrm{B}$ pathway, including homologs of the I-kappa-B kinase (Ikk) complex ${ }^{25}$, two I $\mathrm{B} \alpha$ paralogs, as well as transcription factors RelA, c-Rel, and p100 ${ }^{26}$. Heterologous cell culture assays indicate that zebrafish NF- $\mathrm{KB}$ signaling proteins respond to stimulation by $\mathrm{TNF} \alpha$ or lipopolysaccharide (LPS) ${ }^{26}$. However, the regulation and function of this signaling pathway in response to microbial challenges in living zebrafish remain unknown.

In this study, we established and used a novel $T g(N F k B: E G F P)$ zebrafish model to elucidate the temporal and spatial pattern of NF- $\mathrm{KB}$ activation (EGFP expression) in the whole body during development and microbial colonization. We identify intestinal and extra-intestinal tissues that are responsive to microbial colonization and investigate the mechanisms underlying microbe-induced host responses.

\section{MATERIALS AND METHODS}

The Supplementary Materials and Methods present methods used for zebrafish husbandry, functional genomics, zebrafish cell culture, Western immunoblot analysis, immunofluorescence assays of zebrafish cells, transfection and luciferase activity assays, construction of transgenic lines, in vivo imaging, wholemount RNA in situ hybridization,chromatin immunoprecipitation, quantitative reverse transcription polymerase chain reaction, immunofluorescence and confocal microscopy of zebrafish tissues, morpholino injection, flow cytometry analysis, and statistical methods.

\section{RESULTS}

\section{Functional genomic comparisons reveal host responses to the microbiota in whole zebrafish larvae}

To define the biological processes regulated by the commensal microbiota in zebrafish hosts, we conducted a microarray-based functional genomic comparison of gene expression in whole 6dpf GF zebrafish larvae to age-matched ex-GF zebrafish colonized since $3 \mathrm{dpf}$ with a conventional zebrafish microbiota (conventionalized or CONVD). This comparison revealed 200 zebrafish transcripts that were differentially expressed in GF compared to CONVD larvae (Tables S1-2). Many of these transcripts are expressed in the developing digestive tract of conventionally-raised (CONV-R) zebrafish (Fig. S1) ${ }^{27}$ or regulated by the commensal microbiota in the zebrafish digestive tract ${ }^{28}$, suggesting that the zebrafish digestive tract is robustly responsive to the microbiota (see Supplemental Results and Table S1). Functional categorization of these 200 microbiota-regulated transcripts revealed enrichment for genes involved in humoral and cell-mediated innate immunity as well as metabolism of lipids and other small molecules (Tables S3-4). Based on existing knowledge of vertebrate genes that are directly regulated by NF- $\mathrm{KB}$, we identified 26 zebrafish transcripts that are differentially expressed in response to the normal microbiota, and also are homologous to mammalian genes directly regulated by the NF- $\mathrm{kB}$ pathway (Table S5 and Figure S2). These results suggest that NF- $\mathrm{KB}$ might serve a central role in mediating host responses to the microbiota in zebrafish.

\section{The zebrafish NF-kB pathway responds to microbial stimuli in vitro}

To determine if the zebrafish NF- $\mathrm{kB}$ pathway responds to microbial stimuli, we first interrogated the pathway in the zebrafish PAC2 fibroblast cell line. The human I $\mathrm{B} B \alpha$ protein

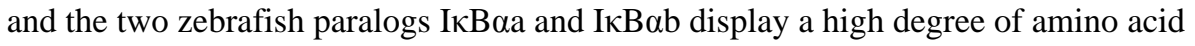
sequence conservation, including conservation of the two serine consensus phosphoacceptor 
sites responsible for signal-induced IKB degradation ${ }^{26}$. LPS stimulation of zebrafish PAC2 embryonic fibroblast cells resulted in a rapid increase in I $\mathrm{B} \alpha$ phosphorylation as revealed by Western blot analysis (Fig. 1A). In addition, immunofluorescence assays revealed strong RelA nuclear staining in LPS-stimulated PAC2 cells compared to unstimulated controls (Fig. 1B).

We next sought to test the impact of the zebrafish NF- $\mathrm{kB}$ signaling pathway on expression of a predicted downstream target gene encoding the IкBaa protein (Table S5). Exposure of PAC2 cells to LPS resulted in time-dependent induction of $i k b a a$ mRNA accumulation (Fig. 1C). Bioinformatic analysis revealed three potential NF- $\mathrm{kB}$ binding sites in the zebrafish ikbaa promoter region located at position $-160,-595$ and -1893 relative to the transcription start site (data not shown). Chromatin immunoprecipitation analysis showed that LPS robustly induced RelA recruitment to the NF- $\mathrm{KB}$ site located at position -595 of the $i k b a a$ promoter (Fig. 1D) but not at the other two positions (data not shown). To further investigate the relationship between NF- $\mathrm{KB}$ signaling and microbe-induced ikbaa gene expression, we constructed an ikbaa-luciferase reporter plasmid (pikbaa:Luc). Luciferase activity increased 2.4-fold in pikbaa:Luc-transfected zebrafish ZFL liver cells following LPS stimulation (Fig. 1E). In accordance, treatment with NF-kB Activation Inhibitor (NAI) ${ }^{29}$ strongly reduced LPS-induced ikbaa mRNA accumulation in PAC2 cells (Fig. 1F). These findings demonstrate that the bacterial factor LPS induces NF- $\kappa B$ signaling and expression of NF- $\mathrm{KB}$ target genes in zebrafish cells.

To test whether the zebrafish NF- $\mathrm{kB}$ pathway is responsive to complex bacterial stimuli, we exposed zebrafish cells to bacterial cell lysate. The Gram-negative $\gamma$-proteobacterium Pseudomonas aeruginosa has been established as a model for analysis of commensal and pathogenic host-bacterial interactions in the zebrafish system ${ }^{30-34}$. We found that cell lysates from wild-type $P$. aeruginosa strain PAK rapidly $(30 \mathrm{~min})$ induced $i k b a a \mathrm{mRNA}$ accumulation in PAC2 cells (Fig. 1C). P. aeruginosa lysate also robustly induced luciferase activity 7.1-fold in pikbaa:Luc-transfected ZFL cells (Fig. 1E), suggesting that the zebrafish NF- $\kappa \mathrm{B}$ pathway is highly sensitive to $P$. aeruginosa products.

\section{Transgenic NFkB:EGFP reporter zebrafish reveal dynamic patterns of NF-kB activity in vivo}

To elucidate the patterns of NF- $\mathrm{BB}$-dependent gene transcription, we constructed an expression vector encoding the EGFP under the transcriptional control of NF- $\mathrm{\kappa B}$ recognition sequences (pNFkB:EGFP) (Fig. 2A). pNFkB:EGFP-transfected PAC2 cells displayed enhanced EGFP expression following LPS stimulation compared to unstimulated cells, which was blocked by the NF-kB inhibitor Bay 11-7085 (Fig. S3). This suggests that EGFP expression from the pNFkB:EGFP plasmid in zebrafish cells is NF- $\kappa B$-dependent.

We next generated transgenic zebrafish harboring the pNFkB:EGFP transgene to monitor the spatial and temporal pattern of NF- $\mathrm{KB}$ transcriptional activation in living animals. To define the spatial pattern of NF- $\kappa B$ activation as a function of host age, we observed EGFP expression in developing CONV-R $T g(N F k B: E G F P)$ zebrafish (see Supplemental Results and Figures S4-6 for details). Briefly, EGFP expression in $T g(N F k B: E G F P)$ zebrafish at 24 hours post-fertilization (hpf) was limited to a small number of cells in multiple tissues including retina, muscle, and neural tube (Figs. 2B and S4A). By 50hpf, EGFP expression was enriched in several specific structures, including the lateral line sensory system, sensory patches of the ear, dorsal root ganglia (DRG), swim bladder primordium, and pharyngeal teeth (Figs. 2C,F and S4B,C). In addition to these tissues, $T g(N F k B: E G F P$ ) zebrafish began expressing EGFP in the intestine by $74 \mathrm{hpf}$, around the time that larvae hatch from their protective chorions (Fig. 2D). Immunofluorescence assays reveal that EGFP expressing cells in the intestine include a subset of secretory cells and absorptive enterocytes (Fig. S6). 
These and other cell types express EGFP into juvenile and adult stages in $T g(N F k B: E G F P)$ zebrafish (Figs. 2, S4, and S5). Together, these results indicate that the zebrafish NF-кB pathway is active in a diverse set of cell types from embryogenesis through adult stages, raising the possibility that NF- $\mathrm{KB}$ pathway activation in these cell types may be differentially regulated by environmental and physiological factors.

\section{Microbial colonization of Tg(NFkB:EGFP) zebrafish stimulates dynamic spatial and temporal patterns of NF-kB activity}

To test the effect of the microbiota on zebrafish NF- $\mathrm{KB}$ activation in vivo, we performed RelA chromatin immunoprecipitation on whole 6dpf GF and CONVD Tg(NFkB:EGFP) zebrafish. RelA binding to the NF- $\mathrm{KB}$ enhancer in the NFkB:EGFP transgene and to the promoter of the endogenous ikbaa gene was significantly elevated in CONVD compared to GF larvae (Fig. 3). This establishes that the NFkB:EGFP transgene is a direct target of the zebrafish NF- $\kappa$ B pathway, and that the microbiota stimulates NF- $\mathrm{\kappa B}$ activity in whole zebrafish larvae.

To determine the spatial and temporal distribution of NF- $\mathrm{KB}$ response to the microbiota, we monitored in vivo patterns of EGFP fluorescence in GF and CONVD Tg(NFkB:EGFP) zebrafish. At 3dpf, GF zebrafish express EGFP in many of the same cells types as CONV-R zebrafish (Figs. 2 and 4), suggesting that NF- $\kappa B$ activation in those cells is not dependent on microbial stimuli. Colonization of 3dpf GF $T g(N F k B: E G F P)$ zebrafish with a microbiota for 24 hours was not sufficient to induce gross alterations in EGFP fluorescence (Fig. 4B,F). However, CONVD zebrafish displayed a significant $8.5 \%$ increase in mean EGFP fluorescence compared to age-matched GF controls by $5 \mathrm{dpf}$ (Fig. 4C, F), and continuing through 6dpf (16.2\% increase; Fig. 4D, F) and 8dpf (16.6\% increase; Fig. 4E, F). Because NF- $\kappa B$ function is essential for zebrafish embryogenesis (see Supplemental Results and Fig. S7) ${ }^{25,26}$, we transiently blocked the pathway using NAI to test whether microbial induction of the EGFP reporter during larval stages was NF-kB-dependent. The ability of the microbiota to induce EGFP expression in 6dpf CONVD $T g(N F k B: E G F P)$ animals was significantly reduced by treatment with NAI from 3-6dpf (Fig. 4F). GF $T g(N F k B: E G F P$ ) larvae treated with NAI did not show a decrease in EGFP fluorescence compared to untreated GF animals (Fig. 4F). These data indicate that colonization by the microbiota induces NF- $\mathrm{kB}$ pathway activation in a dynamic temporal pattern.

To identify the anatomic sites of NF- $\mathrm{KB}$ activation following microbial colonization, we quantified EGFP fluorescence in specific tissues of 6dpf GF and CONVD $T g(N F k B: E G F P)$ larvae. CONVD larvae displayed significantly elevated EGFP expression in multiple digestive tract organs compared to GF controls, including liver, swim bladder, and multiple segments of the intestine (Fig. 5B). However, no significant difference was detected in cells associated with lateral line neuromasts, DRG, or muscle (Fig. 5B). Comparisons of 6dpf GF and CONVD zebrafish from a second independent $T g(N F k B: E G F P)$ line revealed a similar pattern of microbiota-induced and constitutive EGFP expression (data not shown), suggesting that these patterns of microbial induction are not due to transgene position effect. The commensal microbiota therefore stimulates robust NF- $\mathrm{kB}$ activation (EGFP) in intestine and extra-intestinal organs of the zebrafish digestive tract, without salient activation in other non-digestive tract tissues.

To determine the cellular origins of the NF- $\mathrm{KB}$ responses to the microbiota in the intestinal epithelium, we utilized $T g(-4.5 i n t e s t i n a l$ fatty acid binding protein [ifabp]:DsRed) zebrafish that express DsRed specifically in intestinal epithelial cells (IECs) (Fig. S8). We used flow cytometry to isolate DsRed-expressing IECs from 6dpf double-transgenic $T g(-4.5$ ifabp:DsRed)(NFkB:EGFP) zebrafish raised under GF or CONVD conditions. The percentage of DsRed-positive IECs that also express EGFP was similar in 6dpf CONVD and 
GF Tg(-4.5ifabp:DsRed)(NFkB:EGFP) zebrafish larvae [513/890 (57.6\%) DsRed-positive IECs from 100 GF larvae, and 321/495 (64.8\%) DsRed-positive IECs from 67 CONVD larvae]. In contrast, the mean and median EGFP fluorescence levels among EGFP-positive IECs were markedly higher in CONVD compared to GF controls (Fig. 5C). This suggests that microbial colonization results in increased NF- $\mathrm{KB}$ activity (EGFP) in a distinct population of IECs, without affecting the size of that IEC population. Moreover the percentage of DsRed-positive IECs in CONVD animals with EGFP levels above the mean and median EGFP levels in GF DsRed-positive IECs was 38.3\% and 69.3\% respectively, indicating that the presence of the microbiota induced the NF- $\mathrm{KB}$ reporter broadly across this IEC population. To determine which IEC lineages respond to the microbiota, we conducted immunofluorescence analysis on IECs in Tg(-4.5ifabp:DsRed) zebrafish to reveal that DsRed expression colocalizes with the brush border marker 4E8 but not the secretory cell marker 2F11 (Fig. S8) ${ }^{35}$. This indicates that the increased NF-kB reporter activity that occurs within the intestinal epithelium in response to the micobiota is due at least in part to $\mathrm{NF}-\kappa \mathrm{B}$ activity in absorptive enterocytes. Together our data indicate that microbial colonization results in elevated NF- $\mathrm{kB}$ activation (EGFP) in multiple tissues and cell types within the digestive tract.

\section{NF-KB and myd88 mediate a subset of innate immune responses to the microbiota}

We used semi-quantitative RNA wholemount in situ hybridization (WISH) to test the relationship between microbiota-induced NF- $\mathrm{kB}$ activation and expression of putative NF$\kappa \mathrm{B}$ target genes (Table S1). Transcripts encoding complement factor $b(c f b)$ were enriched in the liver of 6dpf CONVD zebrafish compared to GF controls (Fig. 6A), whereas serum amyloid a (saa) mRNA was elevated in liver, swim bladder, and posterior intestine of CONVD versus GF larvae (Fig. 6B). Intriguingly, microbial induction of $c f b$ and $s a a$ expression occurred in the same digestive tract organs as microbial induction of EGFP in $T g(N F k B: E G F P$ ) larvae (Fig. 5). Quantitative RT-PCR analysis of whole 6dpf larvae revealed that microbial induction of $c f b$ and $s a a$ expression can be significantly attenuated by treatment with NAI (Fig. 6D, Tables S6-S7), establishing that microbial induction of $c f b$ and $s a a$ is NF-kB-dependent.

The adapter protein Myd88 is involved in TLR/IL-1/IL-18 receptor signaling and is upstream of the NF-kB transcriptional system ${ }^{5}$. Morpholino knockdown of myd88 in GF and CONVD zebrafish (Fig. S7) showed that microbial induction of saa expression was significantly reduced in myd88 morphants compared to animals injected with standard control morpholino (Fig. 6E). In contrast, microbial induction of $c f b$ expression was only slightly attenuated in myd88 morphants (Fig. 6E). These results establish that microbiota stimulates NF- $\mathrm{KB}-$ dependent expression of innate immune response genes in diverse tissues in the digestive tract, and indicates that some of these responses are dependent on myd 88 function.

To test whether NF- $\mathrm{kB}$ and $m y d 88$ are required for induction of cell-mediated innate immune responses, we evaluated myeloperoxidase (mpo, also called myeloid specific peroxidase or $m p x$ ), a marker of the neutrophil lineage ${ }^{36,37}$. Semi-quantitative WISH revealed that mpo mRNA levels in 6dpf GF animals were markedly reduced compared to age-matched CONVD counterparts (Fig. 6C), indicating that the microbiota is an important factor in neutrophil development and/or survival. In contrast to $s a a$ and $c f b$, qRT-PCR assays revealed that microbial induction of mpo was not significantly altered by NAI treatment or myd88-MO injection (Fig. 6D and E). This suggests that at least a subset of cell-mediated innate immune responses to the commensal microbiota in zebrafish may not require NF-kB or myd88 function. 


\section{NF-kB activation in intestinal and extra-intestinal tissues is sensitive to bacterial flagellar function}

To determine whether NF- $\mathrm{KB}$ activity level in distinct zebrafish tissues is sensitive to variations in bacterial genotype, we colonized 3dpf GF Tg(NFkB:EGFP) larvae with a single bacterial species, $P$. aeruginosa strain PAK. Mono-association with wild-type PAK induced NF- $\mathrm{\kappa B}$ activity in many of the same tissues as the unfractionated microbiota, including intestine and liver (Fig. 7A,B,E). In a previous study, we found that $P$. aeruginosa flagellar function is required for stimulation of innate immune gene expression ${ }^{30}$, but the role of bacterial flagella in zebrafish NF- $\mathrm{kB}$ activation remained unknown. We colonized GF $T g(N F k B: E G F P)$ larvae at $3 \mathrm{dpf}$ with PAK strains containing deletions of genes encoding FliC flagellin $(\triangle f l i C)$ or the flagellar stator proteins MotABCD $(\triangle m o t A B C D)$. Both $\triangle$ fliC and $\triangle m o t A B C D$ strains achieved densities in the zebrafish intestine that were similar to the wild-type parent strain $(\mathrm{P}=0.07$, and $\mathrm{P}=0.49$, respectively), confirming that flagellar function is dispensable for gut colonization ${ }^{30}$. Interestingly, EGFP fluorescence in $T g(N F k B: E G F P)$ zebrafish colonized with PAK $\triangle f l i C$ or $\triangle m o t A B C D$ was indistinguishable from GF controls in several tissues, including the intestine and liver (Fig. 7). These observations indicate that NF- $\mathrm{KB}$ activation in digestive tract tissues is sensitive to bacterial flagellar function, and demonstrate the utility of $T g(N F k B: E G F P)$ zebrafish to report the effect of bacterial genotype on tissue-specific NF- $\kappa \mathrm{B}$ activity in living animals.

\section{DISCUSSION}

NF- $\kappa B$ genes are ancient conserved features of metazoan genomes ${ }^{38,39}$ however relatively little is known about their functions across different metazoan lineages. Our work provides new insights into the impact of the microbiota on zebrafish NF- $\mathrm{kB}$ activity. We show that LPS exposure of zebrafish cells results in rapid phosphorylation of endogenous I $\mathrm{B} \alpha$ protein accompanied by nuclear translocation of RelA, establishing that these aspects of canonical NF- $\kappa \mathrm{B}$ pathway activation are conserved in zebrafish cells. Moreover, we provide multiple lines of cell culture and in vivo evidence that zebrafish ikbaa is a bona fide NF- $\mathrm{KB}$ target gene, similar to its mammalian homologs ${ }^{40}$. Although divergent functions for several TLR/ NF-KB pathway members have been described (i.e., $i k k 1$ and $t l r 4 a l t l r b$ ) $25,41,42$, our data indicate that the canonical NF- $\mathrm{kB}$ pathway is conserved in zebrafish and is responsive to microbial stimulation.

Our validations of $T g(N F k B: E G F P)$ zebrafish (Figs. 1,3,4,S3) indicate that this reporter system can serve as a useful tool to monitor the temporal and spatial patterns of NF- $\kappa B$ activation. We observed relatively little NF- $\kappa$ B activity in zebrafish through 1dpf, similar to the pattern of NF- $\mathrm{kB}$ reporter expression in early mouse embryos ${ }^{19}$. Beginning in later embryonic stages, $T g(N F k B: E G F P)$ fish displayed strong NF- $\kappa B$ activity in multiple tissues including those within the peripheral nervous system and digestive tract. Comparison of our results to reported patterns of NF- $\kappa \mathrm{B}$ activation in mice indicates that NF- $\mathrm{KB}$ activation may be a conserved feature in multiple vertebrate tissues (see Supplemental Results and Figs. 2 and Tables S4-S6).

Comparisons of GF and CONVD larvae disclose that zebrafish host responses to the microbiota are concentrated in the digestive tract. First, our functional genomic comparison of GF and CONVD larvae revealed that many of the transcripts that were increased in response to microbial colonization are also enriched in the digestive tract of developing CONV-R zebrafish (Figure S1 and Table S1) ${ }^{27}$. This indicates that the zebrafish digestive tract is robustly responsive to microbial colonization, and supports the model that the microbiota promotes maturation of the zebrafish digestive tract. Second, $T g(N F k B: E G F P$ ) zebrafish revealed that NF- $\kappa B$ response to the microbiota was most significant in the organs of the digestive tract. Using flow cytometry analysis of IECs from $T g(-4.5 i f a b p: D s R e d)$ 
(NFkB:EGFP) zebrafish, we revealed that microbiota stimulates increased NF- $\mathrm{KB}$ activation (EGFP fluorescence) in a subpopulation of DsRed-positive IECs without affecting the size of that DsRed/EGFP-positive IEC subpopulation (Fig. 5C). Our immunofluorescence analysis indicates that these responsive IECs are absorptive enterocytes. The effect of the microbiota on NF- $\kappa$ B activity in intestinal cell lineages remains to be elucidated, however analysis of the secretory cell marker $2 \mathrm{~F} 11^{35}$ in the intestines of GF and CONVD $T g(N F k B: E G F P)$ zebrafish revealed no significant differences in the percentage of 2F11positive secretory cells that express the EGFP reporter in intestinal segment 1 (Fig. S9). Colonization of GF NF- $\kappa$ B reporter mice with a normal mouse microbiota also induced reporter activity in IECs ${ }^{16}$, indicating that NF- $\mathrm{\kappa B}$ activation in IECs is a conserved feature of the intestinal response to commensal microbes. As in the mouse, NF- $\mathrm{kB}$ reporter activity was relatively low in the zebrafish liver under homeostatic conditions ${ }^{19}$. However, the zebrafish liver displayed significantly elevated NF- $\kappa \mathrm{B}$ activity upon colonization with a normal microbiota, consistent with the role of the liver in production of acute phase products in fish as well as mammals ${ }^{43}$. In contrast, NF- $\mathrm{kB}$-derived responses in non-digestive tract tissues were relatively minor. Taken together, our data provide the unexpected insight that the digestive tract is the dominant site of host response to the microbiota, despite the exposure of all external surfaces of the animal to the surrounding microbial environment. This may occur because digestive tract organs are inherently more sensitive to microbial stimuli than other tissues. This may also be due, at least in part to the fact that the microbial community that assembles in the zebrafish intestinal lumen reaches higher densities (approximately $10^{9-10} \mathrm{cfu} / \mathrm{mL}$ in each 6dpf CONVD larvae, based on an estimated $10 \mathrm{~nL}$ total luminal volume) than that of the surrounding water $\left(10^{4-5} \mathrm{cfu} / \mathrm{mL}\right.$ in $6 \mathrm{dpf}$ CONVD larvae housing water; data not shown).

Interestingly, colonization of GF $T g(N F k B: E G F P)$ zebrafish larvae with a normal zebrafish microbiota resulted in elevated NF- $\mathrm{KB}$ activation in digestive tract tissues exposed to the external environment (i.e., intestine and swim bladder) as well as internal tissues (i.e., liver). The mechanisms by which commensal microbes stimulate responses in extra-intestinal tissues such as liver remain unclear. It is possible that responses at extra-intestinal sites may be evoked by microbial metabolites ${ }^{44}$ or products such as LPS ${ }^{45,46}$, which could be absorbed across the intestinal barrier and released into circulation. Alternatively, microbes may stimulate responses locally in the intestine, resulting in mucosal production of host cytokines and other effector molecules that enter circulation to evoke responses at extraintestinal sites ${ }^{8}$. The function of extra-intestinal NF- $\mathrm{KB}$ responses to the microbiota remains unclear, but could represent an important communication axis alerting extra-intestinal tissues to potentially stressful events (i.e., microbial colonization).

Our results in $T g(N F k B: E G F P)$ zebrafish are consistent with previous studies in mammals indicating that the NF- $\mathrm{KB}$ activity can exist in 'inducible' as well as 'constitutive' states. Constitutive activation of NF- $\mathrm{kB}$ observed using multiple mammalian reporter systems (e.g., EGFP, luciferase, and $\beta$-galactosidase) is not inhibited by pharmacological or molecular approaches, which are able to block induction by microbial stimuli $16,18,47-51$. Similarly, we find constitutive NF- $\mathrm{BB}$ activity (EGFP expression) in multiple tissues of both GF and CONVD $T g(N F k B: E G F P)$ zebrafish, with microbial colonization inducing EGFP levels in only a subset of those tissues. This inducible EGFP expression was inhibited by exposure to NF- $\mathrm{KB}$ inhibitor NAI, whereas EGFP expression levels in GF $T g(N F k B: E G F P)$ zebrafish were not saliently affected (Fig. 4). It is estimated that the NF-kB pathway can be activated by $>150$ different stimuli, only some of which are of microbial origin ${ }^{52}$. Constitutive NF$\kappa \mathrm{B}$ activation in GF animals could result from stimulation by non-microbial factors, or shuttling and/or posttranslational regulation of various NF- $\kappa \mathrm{B}$ transcriptional subunits already present in the nucleus 53,54 . 
Transgenic zebrafish lines such as $T g(N F k B: E G F P)$, which report the activity of specific signal transduction pathways provide new opportunities to identify genes and molecules that control the activity of that pathway in specific tissues and developmental stages. In proof-ofconcept experiments, we used $P$. aeruginosa as a model gut bacterium to test whether $T g(N F k B: E G F P)$ reporter activity in different tissues is sensitive to variations in bacterial genotype. Whereas colonization of GF zebrafish with this single bacterial species was sufficient to induce NF- $\kappa B$ reporter activity in intestinal as well as extra-intestinal tissues, mono-association with mutants defective for flagellar filament biogenesis $(\triangle \mathrm{fliC})$ or rotation $(\triangle m o t A B C D)$ resulted in attenuated NF- $\mathrm{KB}$ induction in multiple tissues (Fig. 7). Zebrafish $\mathrm{NF}-\kappa \mathrm{B}$ activity in intestinal as well as extra-intestinal tissues is therefore sensitive to bacterial flagellar function, however additional investigation will be required to determine which specific aspects of flagellar function are required to induce NF- $\kappa \mathrm{B}$ activity in distinct tissues. These results establish that the $T g(N F k B: E G F P)$ zebrafish is sufficiently sensitive to distinguish between bacterial genotypes, and could be used to screen for bacterial mutants or products that modulate specific temporal or spatial patterns of NF- $\mathrm{\kappa B}$ activation in zebrafish.

Our results indicate that zebrafish innate immune responses to the microbiota are mediated by at least two distinct signaling mechanisms. We show that microbial induction of humoral immune response genes $s a a$ and $c f b$ is mediated by a NF- $\kappa \mathrm{B}$-dependent mechanism. Morpholino knockdown experiments revealed that microbial induction of $s a a$ also requires myd88, implicating TLRs or receptors for IL-1 or IL-18 in this signaling pathway. The partial attenuation of $c f b$ induction in myd88 morphants could be due to incomplete efficacy of morpholino knockdown (Fig. S7), or regulatory input from an alternate pathway. Surprisingly, microbial induction of the neutrophil marker mpo was independent of NF- $\kappa \mathrm{B}$ and myd 88 function, indicating that different signaling mechanisms mediate this cellular response. Further investigation will be required to identify the specific receptors mediating NF- $\kappa \mathrm{B}$ - and myd88-dependent responses, as well as the additional mechanisms underlying neutrophil responses to the commensal microbiota.

In conclusion, we report the generation and validation of $T g(N F k B: E G F P)$ zebrafish, and demonstrate that microbial colonization induces NF- $\kappa$ B activation and target gene expression in intestinal as well as extra-intestinal tissues in the digestive tract. $T g(N F k B: E G F P)$ zebrafish represents a valuable system to interrogate the relationship between microorganisms and the function of NF- $\mathrm{kB}$ signaling in multiple anatomical sites. We anticipate that this reporter approach will be broadly applicable to other signaling and transcriptional regulatory mechanisms in the zebrafish model, facilitating combinatorial in vivo real-time analysis of transcriptional responses in diverse cell types and microbial environments.

\section{Supplementary Material}

Refer to Web version on PubMed Central for supplementary material.

\section{Acknowledgments}

Grant Support: National Institutes of Health grants DK034987, DK081426, DK073695, DK047700, DK073338, and OD006486; the University of North Carolina at Chapel Hill; Pew Scholars Program in the Biomedical Sciences.

The authors are grateful to Jeffrey Gordon for his support; Maria Abreu, Albert Baldwin, Alex Nechiporuk, David Stock, Ivana Semova, Gray Camp, and Pam Hesker for helpful comments on the manuscript; to Kirk McNaughton for valuable technical assistance; to Carsten Stuckenholtz and Nathan Bahary for sharing data prior to publication; to Julian Lewis and Michael Pack for sharing antibodies; to Sean Burgess for providing zebrafish cell lines; and to Shannon Fisher and Jennifer Rhodes for providing plasmids. 


\section{Abbreviations}

$\begin{array}{ll}\boldsymbol{c f b} & \text { complement factor } b \\ \text { CONVD } & \text { conventionalized } \\ \text { CONV-R } & \text { conventionally-raised } \\ \text { dpf } & \text { days post-fertilization } \\ \text { EGFP } & \text { enhanced green fluoresent protein } \\ \text { GI } & \text { gastrointestinal } \\ \text { GF } & \text { germ-free } \\ \text { ifabp } & \text { intestinal fatty acid binding protein } \\ \text { LPS } & \text { lipopolysaccharide } \\ \text { MAMP } & \text { microbe-associated molecular pattern } \\ \text { mpo } & \text { myeloperoxidase } \\ \text { NF- } \mathbf{~ B ~} & \text { nuclear factor kappa-light-chain-enhancer of activated B cells } \\ \text { NAI } & \text { NF- } \text { - B Activation Inhibitor } \\ \text { PRR } & \text { pattern recognition receptor } \\ \text { saa } & \text { serum amyloid } a \\ \text { TLR } & \text { Toll-like receptor } \\ \text { WISH } & \text { wholemount RNA in situ hybridization }\end{array}$

\section{References}

1. Qin J, Li R, Raes J, et al. A human gut microbial gene catalogue established by metagenomic sequencing. Nature. 2010; 464:59-65. [PubMed: 20203603]

2. Backhed F, Ley RE, Sonnenburg JL, et al. Host-bacterial mutualism in the human intestine. Science. 2005; 307:1915-20. [PubMed: 15790844]

3. Camp JG, Kanther M, Semova I, et al. Patterns and scales in gastrointestinal microbial ecology. Gastroenterology. 2009; 136:1989-2002. [PubMed: 19457423]

4. Leulier F, Lemaitre B. Toll-like receptors--taking an evolutionary approach. Nat Rev Genet. 2008; 9:165-78. [PubMed: 18227810]

5. Takeda K, Akira S. TLR signaling pathways. Semin Immunol. 2004; 16:3-9. [PubMed: 14751757]

6. Bowie A, O'Neill LA. The interleukin-1 receptor/Toll-like receptor superfamily: signal generators for pro-inflammatory interleukins and microbial products. J Leukoc Biol. 2000; 67:508-14. [PubMed: 10770283]

7. Karrasch T, Jobin C. NF-kappaB and the intestine: friend or foe? Inflamm Bowel Dis. 2008; 14:114-24. [PubMed: 17763472]

8. Chen LW, Egan L, Li ZW, et al. The two faces of IKK and NF-kappaB inhibition: prevention of systemic inflammation but increased local injury following intestinal ischemia-reperfusion. Nat Med. 2003; 9:575-81. [PubMed: 12692538]

9. Egan LJ, Eckmann L, Greten FR, et al. IkappaB-kinasebeta-dependent NF-kappaB activation provides radioprotection to the intestinal epithelium. Proc Natl Acad Sci U S A. 2004; 101:2452-7. [PubMed: 14983030]

10. Fukata M, Michelsen KS, Eri R, et al. Toll-like receptor-4 is required for intestinal response to epithelial injury and limiting bacterial translocation in a murine model of acute colitis. Am J Physiol Gastrointest Liver Physiol. 2005; 288:G1055-65. [PubMed: 15826931] 
11. Greten FR, Eckmann L, Greten TF, et al. IKKbeta links inflammation and tumorigenesis in a mouse model of colitis-associated cancer. Cell. 2004; 118:285-96. [PubMed: 15294155]

12. Nenci A, Becker C, Wullaert A, et al. Epithelial NEMO links innate immunity to chronic intestinal inflammation. Nature. 2007; 446:557-61. [PubMed: 17361131]

13. Rakoff-Nahoum S, Hao L, Medzhitov R. Role of toll-like receptors in spontaneous commensaldependent colitis. Immunity. 2006; 25:319-29. [PubMed: 16879997]

14. Rakoff-Nahoum S, Paglino J, Eslami-Varzaneh F, et al. Recognition of commensal microflora by toll-like receptors is required for intestinal homeostasis. Cell. 2004; 118:229-41. [PubMed: 15260992]

15. Steinbrecher KA, Harmel-Laws E, Sitcheran R, et al. Loss of epithelial RelA results in deregulated intestinal proliferative/apoptotic homeostasis and susceptibility to inflammation. J Immunol. 2008; 180:2588-99. [PubMed: 18250470]

16. Karrasch T, Kim JS, Muhlbauer M, et al. Gnotobiotic IL-10-/-;NF-kappa B(EGFP) mice reveal the critical role of TLR/NF-kappa B signaling in commensal bacteria-induced colitis. J Immunol. 2007; 178:6522-32. [PubMed: 17475882]

17. Magness ST, Jijon H, Van Houten Fisher N, et al. In vivo pattern of lipopolysaccharide and antiCD3-induced NF-kappa B activation using a novel gene-targeted enhanced GFP reporter gene mouse. J Immunol. 2004; 173:1561-70. [PubMed: 15265883]

18. Bhakar AL, Tannis LL, Zeindler C, et al. Constitutive nuclear factor-kappa B activity is required for central neuron survival. J Neurosci. 2002; 22:8466-75. [PubMed: 12351721]

19. Schmidt-Ullrich R, Memet S, Lilienbaum A, et al. NF-kappaB activity in transgenic mice: developmental regulation and tissue specificity. Development. 1996; 122:2117-28. [PubMed: 8681793]

20. Wallace KN, Akhter S, Smith EM, et al. Intestinal growth and differentiation in zebrafish. Mech Dev. 2005; 122:157-73. [PubMed: 15652704]

21. Ng AN, de Jong-Curtain TA, Mawdsley DJ, et al. Formation of the digestive system in zebrafish: III. Intestinal epithelium morphogenesis. Dev Biol. 2005; 286:114-35. [PubMed: 16125164]

22. Pham LN, Kanther M, Semova I, et al. Methods for generating and colonizing gnotobiotic zebrafish. Nat Protoc. 2008; 3:1862-75. [PubMed: 19008873]

23. Kanther M, Rawls JF. Host-microbe interactions in the developing zebrafish. Curr Opin Immunol. 2010; 22:10-9. [PubMed: 20153622]

24. Meeker ND, Trede NS. Immunology and zebrafish: spawning new models of human disease. Dev Comp Immunol. 2008; 32:745-57. [PubMed: 18222541]

25. Correa RG, Matsui T, Tergaonkar V, et al. Zebrafish IkappaB kinase 1 negatively regulates NFkappaB activity. Curr Biol. 2005; 15:1291-5. [PubMed: 16051172]

26. Correa RG, Tergaonkar V, Ng JK, et al. Characterization of NF-kappa B/I kappa B proteins in zebra fish and their involvement in notochord development. Mol Cell Biol. 2004; 24:5257-68. [PubMed: 15169890]

27. Stuckenholz C, Lu L, Thakur P, et al. FACS-assisted microarray profiling implicates novel genes and pathways in zebrafish gastrointestinal tract development. Gastroenterology. 2009; 137:132132. [PubMed: 19563808]

28. Rawls JF, Samuel BS, Gordon JI. Gnotobiotic zebrafish reveal evolutionarily conserved responses to the gut microbiota. Proc Natl Acad Sci U S A. 2004; 101:4596-601. [PubMed: 15070763]

29. Tobe $\mathrm{M}$, Isobe $\mathrm{Y}$, Tomizawa $\mathrm{H}$, et al. Discovery of quinazolines as a novel structural class of potent inhibitors of NF-kappa B activation. Bioorg Med Chem. 2003; 11:383-91. [PubMed: 12517433]

30. Rawls JF, Mahowald MA, Goodman AL, et al. In vivo imaging and genetic analysis link bacterial motility and symbiosis in the zebrafish gut. Proc Natl Acad Sci U S A. 2007; 104:7622-7. [PubMed: 17456593]

31. Brannon MK, Davis JM, Mathias JR, et al. Pseudomonas aeruginosa Type III secretion system interacts with phagocytes to modulate systemic infection of zebrafish embryos. Cell Microbiol. 2009

32. Clatworthy AE, Lee JS, Leibman M, et al. Pseudomonas aeruginosa infection of zebrafish involves both host and pathogen determinants. Infect Immun. 2009; 77:1293-303. [PubMed: 19168742] 
33. Rawls JF, Mahowald MA, Ley RE, et al. Reciprocal gut microbiota transplants from zebrafish and mice to germ-free recipients reveal host habitat selection. Cell. 2006; 127:423-33. [PubMed: 17055441]

34. Vasil ML, Stonehouse MJ, Vasil AI, et al. A complex extracellular sphingomyelinase of Pseudomonas aeruginosa inhibits angiogenesis by selective cytotoxicity to endothelial cells. PLoS Pathog. 2009; 5:e1000420. [PubMed: 19424430]

35. Crosnier C, Vargesson N, Gschmeissner S, et al. Delta-Notch signalling controls commitment to a secretory fate in the zebrafish intestine. Development. 2005; 132:1093-104. [PubMed: 15689380]

36. Lieschke GJ, Oates AC, Crowhurst MO, et al. Morphologic and functional characterization of granulocytes and macrophages in embryonic and adult zebrafish. Blood. 2001; 98:3087-96. [PubMed: 11698295]

37. Bennett CM, Kanki JP, Rhodes J, et al. Myelopoiesis in the zebrafish, Danio rerio. Blood. 2001; 98:643-51. [PubMed: 11468162]

38. Sullivan JC, Kalaitzidis D, Gilmore TD, et al. Rel homology domain-containing transcription factors in the cnidarian Nematostella vectensis. Dev Genes Evol. 2007; 217:63-72. [PubMed: 17120026]

39. Gauthier M, Degnan BM. The transcription factor NF-kappaB in the demosponge Amphimedon queenslandica: insights on the evolutionary origin of the Rel homology domain. Dev Genes Evol. 2008; 218:23-32. [PubMed: 18175145]

40. Ito CY, Kazantsev AG, Baldwin AS Jr. Three NF-kappa B sites in the I kappa B-alpha promoter are required for induction of gene expression by TNF alpha. Nucleic Acids Res. 1994; 22:378792. [PubMed: 7937093]

41. Sepulcre MP, Alcaraz-Perez F, Lopez-Munoz A, et al. Evolution of lipopolysaccharide (LPS) recognition and signaling: fish TLR4 does not recognize LPS and negatively regulates NF-kappaB activation. J Immunol. 2009; 182:1836-45. [PubMed: 19201835]

42. Sullivan C, Charette J, Catchen J, et al. The gene history of zebrafish tlr4a and tlr4b is predictive of their divergent functions. J Immunol. 2009; 183:5896-908. [PubMed: 19812203]

43. Bayne CJ, Gerwick L. The acute phase response and innate immunity of fish. Dev Comp Immunol. 2001; 25:725-43. [PubMed: 11602193]

44. Claus SP, Tsang TM, Wang Y, et al. Systemic multicompartmental effects of the gut microbiome on mouse metabolic phenotypes. Mol Syst Biol. 2008; 4:219. [PubMed: 18854818]

45. Cani PD, Amar J, Iglesias MA, et al. Metabolic endotoxemia initiates obesity and insulin resistance. Diabetes. 2007; 56:1761-72. [PubMed: 17456850]

46. Ghoshal S, Witta J, Zhong J, et al. Chylomicrons promote intestinal absorption of lipopolysaccharides. J Lipid Res. 2009; 50:90-7. [PubMed: 18815435]

47. Dave SH, Tilstra JS, Matsuoka K, et al. Amelioration of chronic murine colitis by peptidemediated transduction of the IkappaB kinase inhibitor NEMO binding domain peptide. J Immunol. 2007; 179:7852-9. [PubMed: 18025231]

48. Carlsen H, Moskaug JO, Fromm SH, et al. In vivo imaging of NF-kappa B activity. J Immunol. 2002; 168:1441-6. [PubMed: 11801687]

49. Vykhovanets EV, Shukla S, MacLennan GT, et al. Molecular imaging of NF-kappaB in prostate tissue after systemic administration of IL-1 beta. Prostate. 2008; 68:34-41. [PubMed: 18004768]

50. Austenaa LM, Carlsen H, Hollung K, et al. Retinoic acid dampens LPS-induced NF-kappaB activity: results from human monoblasts and in vivo imaging of NF-kappaB reporter mice. J Nutr Biochem. 2009; 20:726-34. [PubMed: 18926686]

51. Zangani M, Carlsen H, Kielland A, et al. Tracking early autoimmune disease by bioluminescent imaging of NF-kappaB activation reveals pathology in multiple organ systems. Am J Pathol. 2009; 174:1358-67. [PubMed: 19286564]

52. Pahl HL. Activators and target genes of Rel/NF-kappaB transcription factors. Oncogene. 1999; 18:6853-66. [PubMed: 10602461]

53. Ghosh S, Hayden MS. New regulators of NF-kappaB in inflammation. Nat Rev Immunol. 2008; 8:837-48. [PubMed: 18927578]

54. Hayden MS, Ghosh S. Shared principles in NF-kappaB signaling. Cell. 2008; 132:344-62. [PubMed: 18267068] 
A

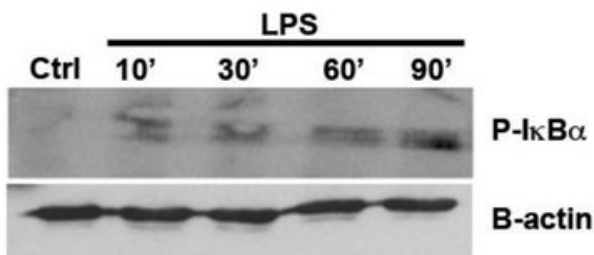

B

Ctrl

LPS 10'

LPS 60'
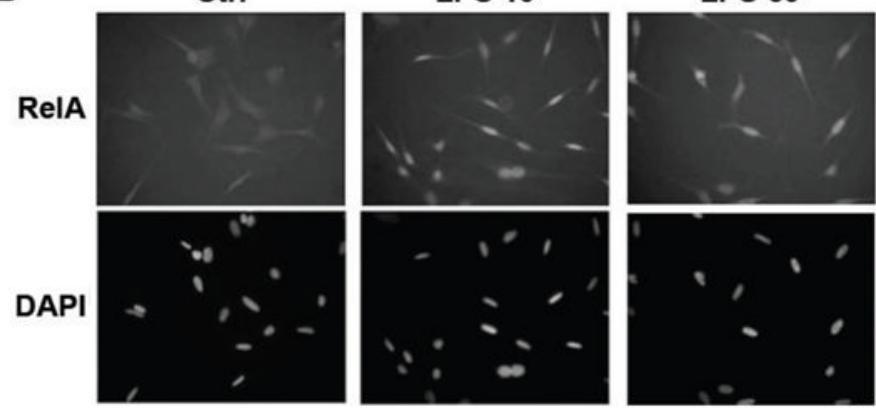

C

D
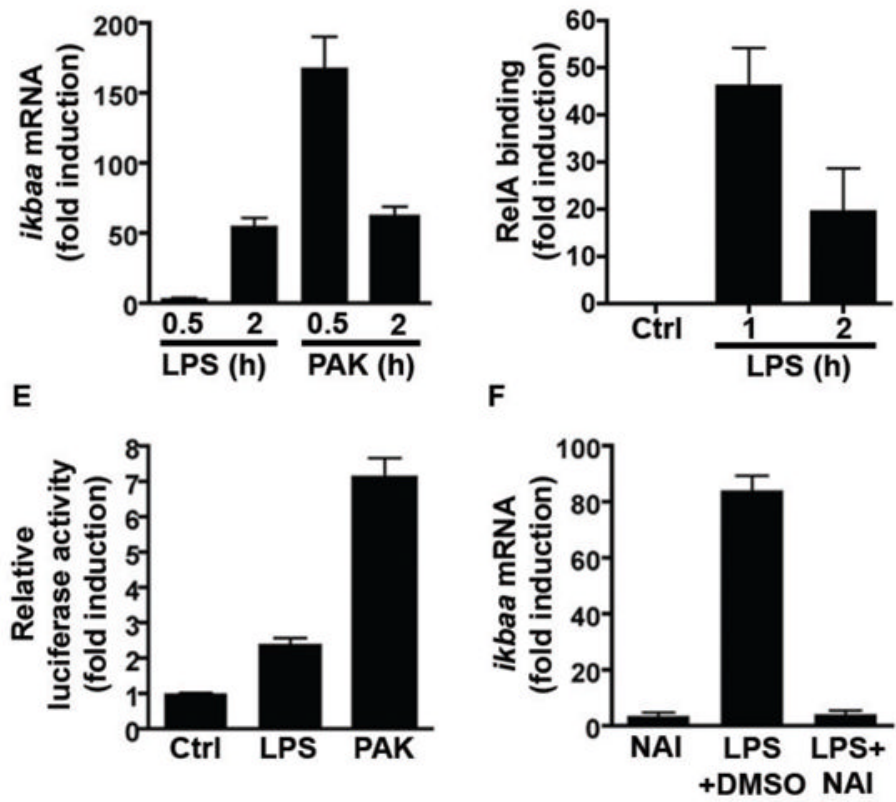

Fig. 1. Bacterial stimulation of zebrafish cell lines results in activation of the canonical NF- $\mathrm{KB}$ pathway and induces expression of NF-кB target genes

(A) Western blot of zebrafish PAC2 cells shows rapid phosphorylation of I $\mathrm{B} \alpha$ proteins following LPS (10 $\mu \mathrm{g} / \mathrm{ml})$ stimulation. (B) Immunofluorescence of PAC2 cells using antiRelA antibody reveals rapid nuclear localization following LPS stimulation. Original magnification set at 400×. (C) qRT-PCR using primers for $i k b a a$, a predicted NF- $\kappa \mathrm{B}$ target gene, demonstrating time-dependent accumulation upon stimulation with LPS $(10 \mu \mathrm{g} / \mathrm{ml})$ or $P$. aeruginosa PAK lysate (43.5 $\mu \mathrm{g} / \mathrm{ml}$; normalized to $18 \mathrm{~S}$ rRNA). (D) Chromatin immunoprecipitation of LPS-stimulated PAC2 cells reveals increased binding of RelA to the zebrafish ikbaa promoter. (E) Zebrafish ZFL cells transfected with ikbaa-luciferase gene reporter (pikbaa:Luc) show increased luciferase activity upon stimulation with LPS (10 $\mu \mathrm{g} /$ $\mathrm{ml})$ or $P$. aeruginosa PAK lysates $(43.5 \mu \mathrm{g} / \mathrm{ml})$. (F) qRT-PCR of $i k b a a$ shows that induction upon LPS stimulation of PAC2 cells is attenuated after treatment with NAI (200 nM; 
normalized to $18 \mathrm{~S}$ rRNA). Data in panels $\mathrm{C}-\mathrm{F}$ are expressed as mean $\pm \mathrm{SD}$. See also Figure S3. 

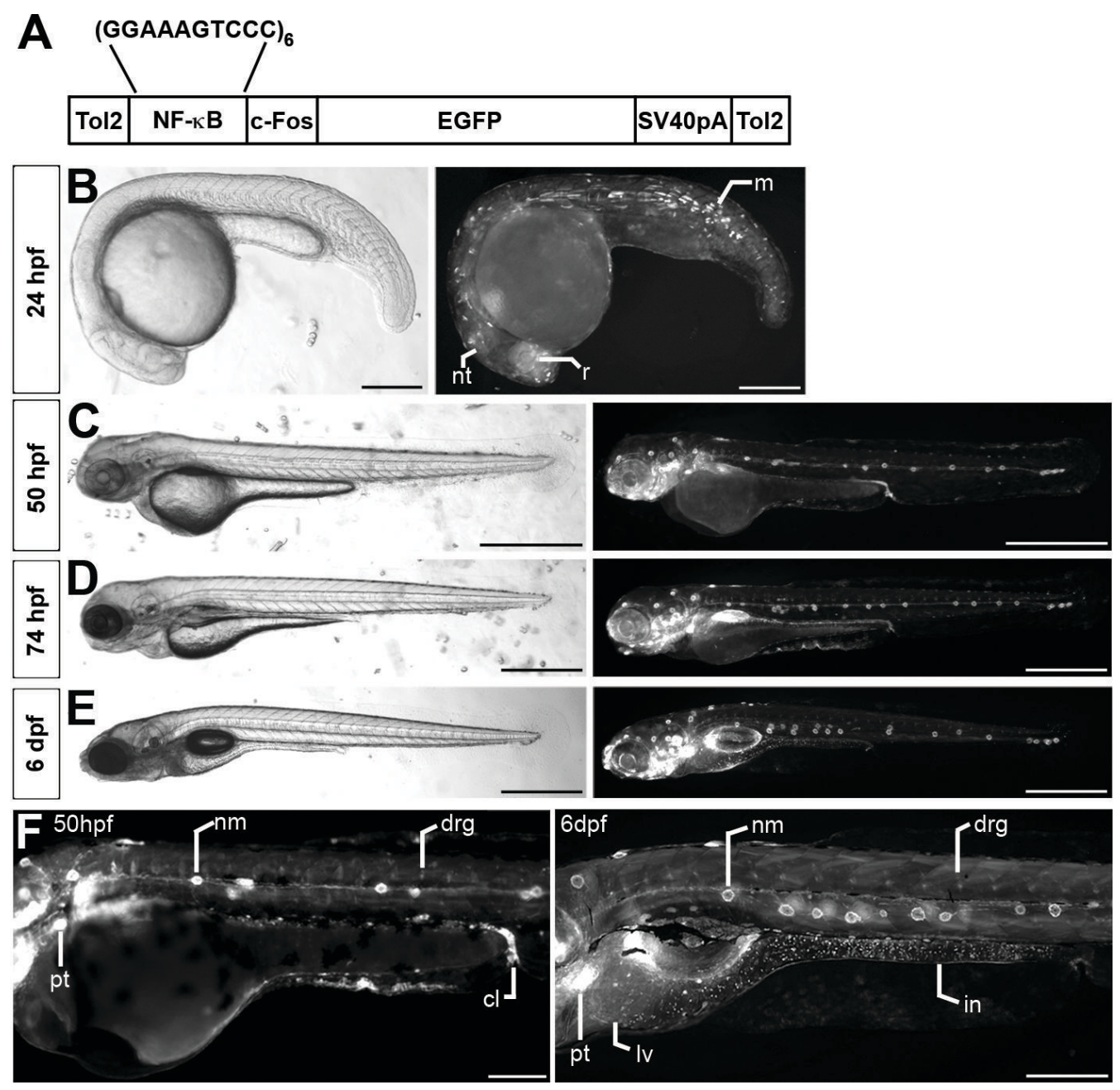

Fig. 2. $T g(N F k B: E G F P)$ zebrafish express EGFP in diverse tissues during development (A) Schematic depiction of pNFkB:EGFP transgene. Brightfield and EGFP fluorescence images of CONV-R $T g(N F k B: E G F P)$ zebrafish at 24hpf (B), 50hpf (C), 74hpf (D), and 6dpf (E). (F) Higher magnification images at 50hpf and 6dpf illustrate diverse tissues expressing EGFP including neuromasts ( $\mathrm{nm})$, dorsal root ganglia (drg), pharyngeal teeth (pt), cloaca

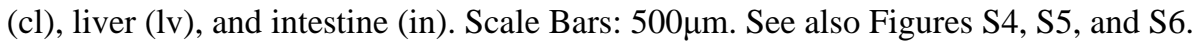



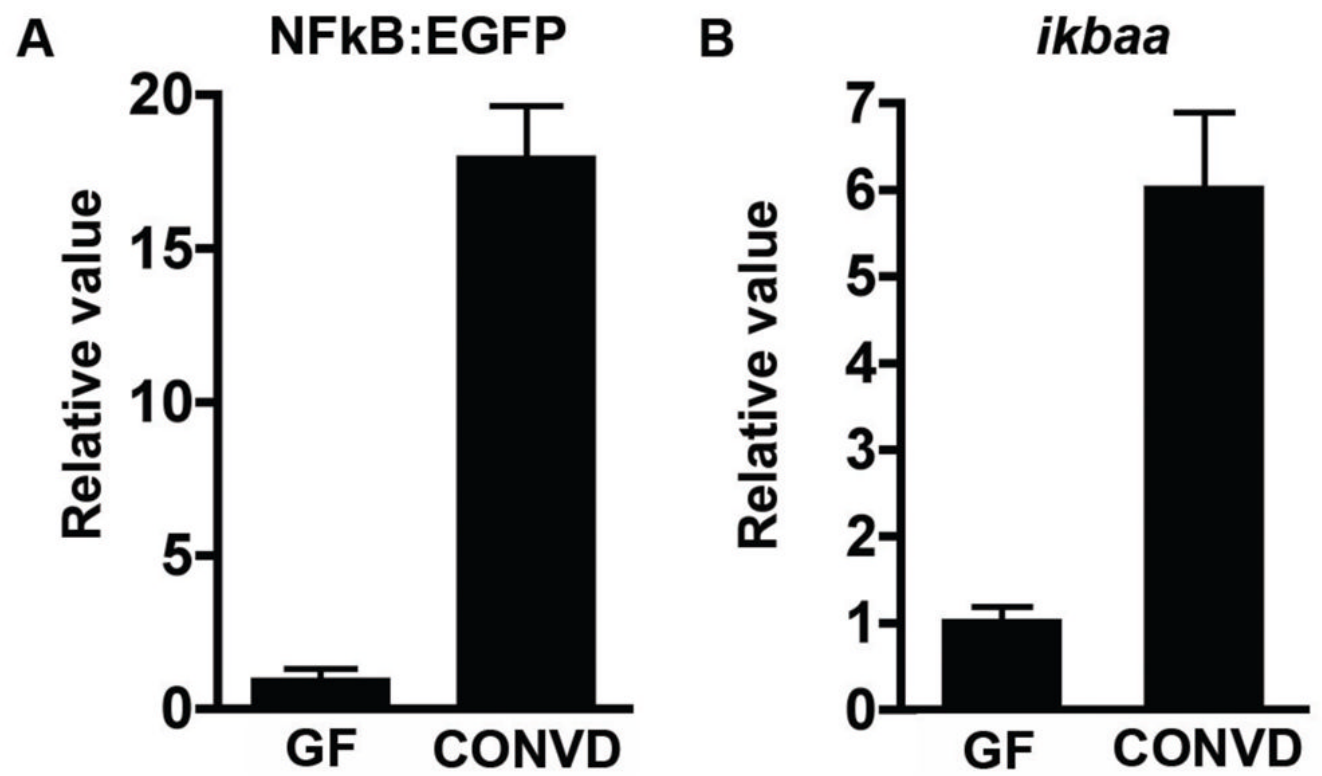

Fig. 3. Colonization of GF $T g(N F k B: E G F P)$ zebrafish with a microbiota stimulates binding of RelA to reporter transgene and ikbaa promoter

Measurement of RelA binding in whole 6dpf GF and CONVD zebrafish (10 fish/condition) was performed using anti-RelA antibody and primers targeting the synthetic NF- $\mathrm{B}$ binding site in the NFkB:EGFP transgene (A) and the promoter of predicted NF- $\kappa$ B target gene $i k b a a(B)$. Results are normalized to internal input controls and expressed as mean folddifference \pm SD. 

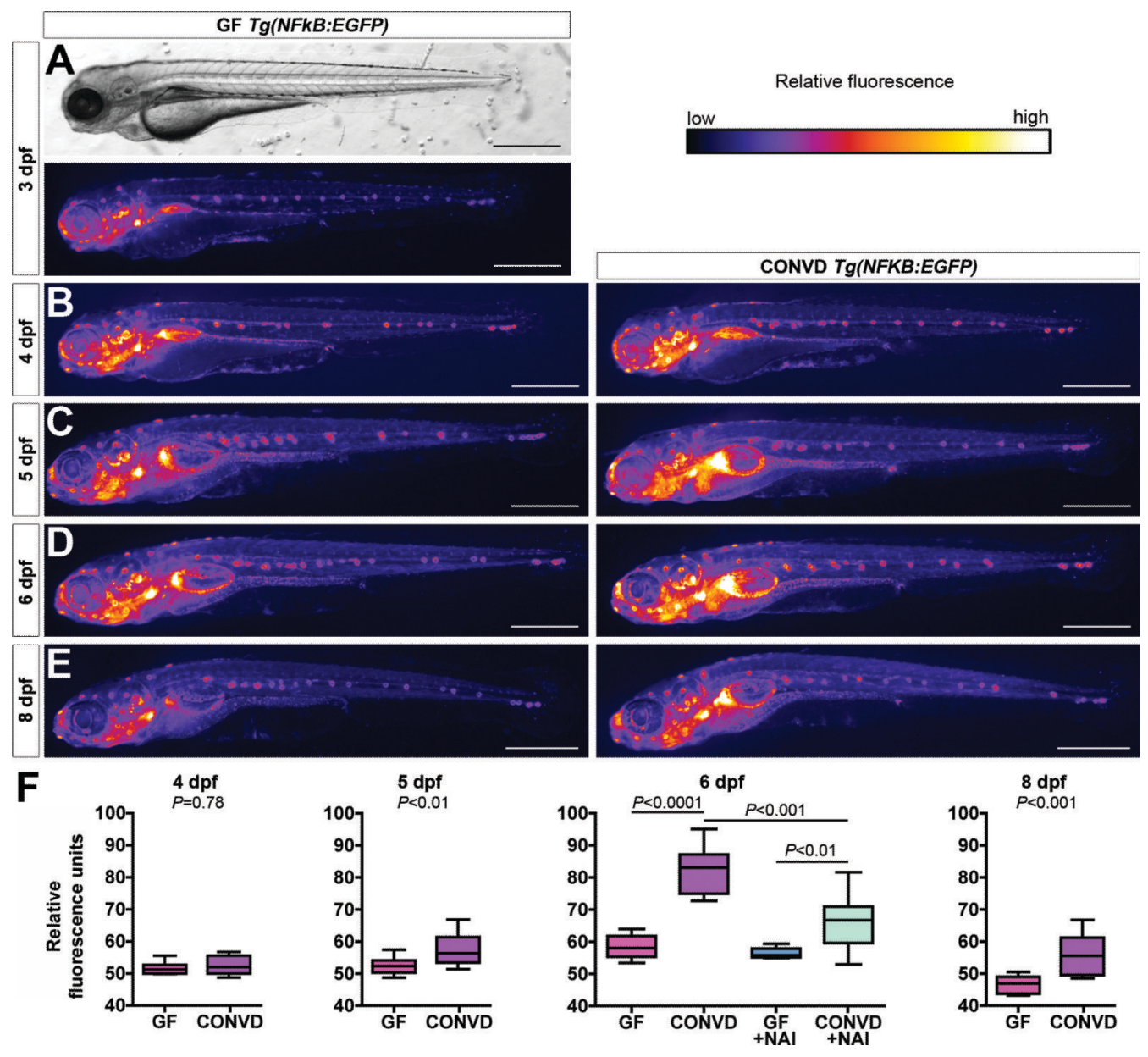

Fig. 4. Conventionalization of GF $\operatorname{Tg}(N F k B: E G F P)$ zebrafish stimulates EGFP expression in diverse cell types

Brightfield (A) and EGFP fluorescence images shown as heatmaps (A-E) of GF 3dpf (A) and GF and CONVD 4dpf (B), $5 \mathrm{dpf}(\mathrm{C}), 6 \mathrm{dpf}(\mathrm{D})$, and $8 \mathrm{dpf} T g(N F k B: E G F P)$ zebrafish (E).

(F) Quantification of relative EGFP fluorescence reveals a significant increase in CONVD compared to GF controls by $5 \mathrm{dpf}$ which continues through $8 \mathrm{dpf}$. Treatment with $200 \mathrm{nM}$ NAI from 3-6dpf results in a significant decrease in relative EGFP fluorescence of 6dpf CONVD zebrafish compared to vehicle-treated CONVD controls (6-10 fish/condition). Scale bars: $200 \mu \mathrm{m}$. 
A
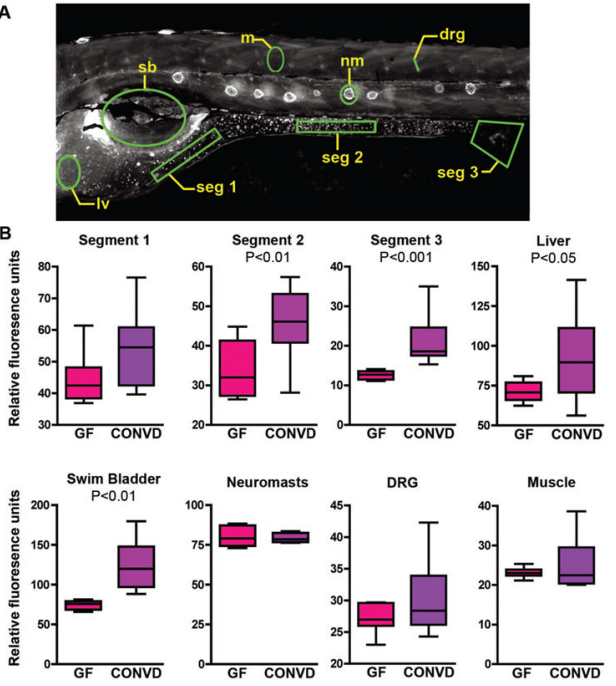

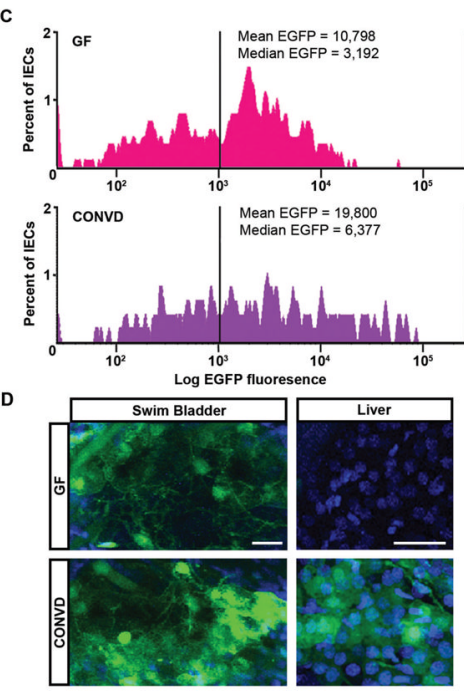

Fig. 5. Microbiota activates NF- $\mathrm{kB}$ in specific tissues in gnotobiotic zebrafish Quantification of relative EGFP fluorescence in specific tissues of 6dpf GF and CONVD $T g(N F k B: E G F P)$ zebrafish. (A) Areas quantified (outlined in green) include intestinal segment 1 (seg 1), segment 2 (seg 2), segment 3 including cloaca (seg 3), liver (lv), swim bladder (sb), neuromasts (nm), dorsal root ganglia (drg), and muscle (m). (B) Quantification of EGFP fluorescence shows significant induction in intestine and other digestive tract tissues of CONVD zebrafish compared to GF controls (10 fish/condition). (C) FACS histogram showing Log EGFP fluorescence in DsRed-positive intestinal epithelial cells (IECs) from 6dpf $T g$ (-4.5ifabp:DsRed)(NFKB:EGFP) GF and CONVD zebrafish. Data is representative of two biological replicates. (D) Wholemount confocal microscopy of EGFP fluorescence in swim bladder and liver in 6dpf GF and CONVD $T g(N F k B: E G F P)$ zebrafish. Scale bars: $10 \mu \mathrm{m}$. 

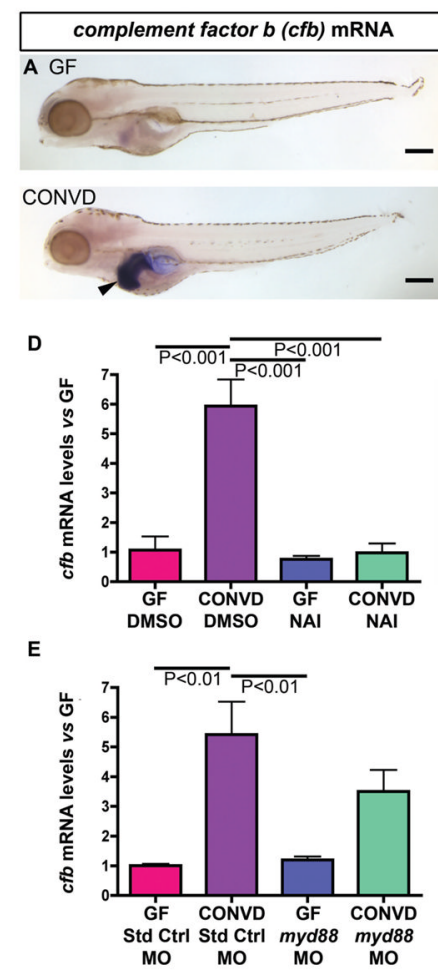
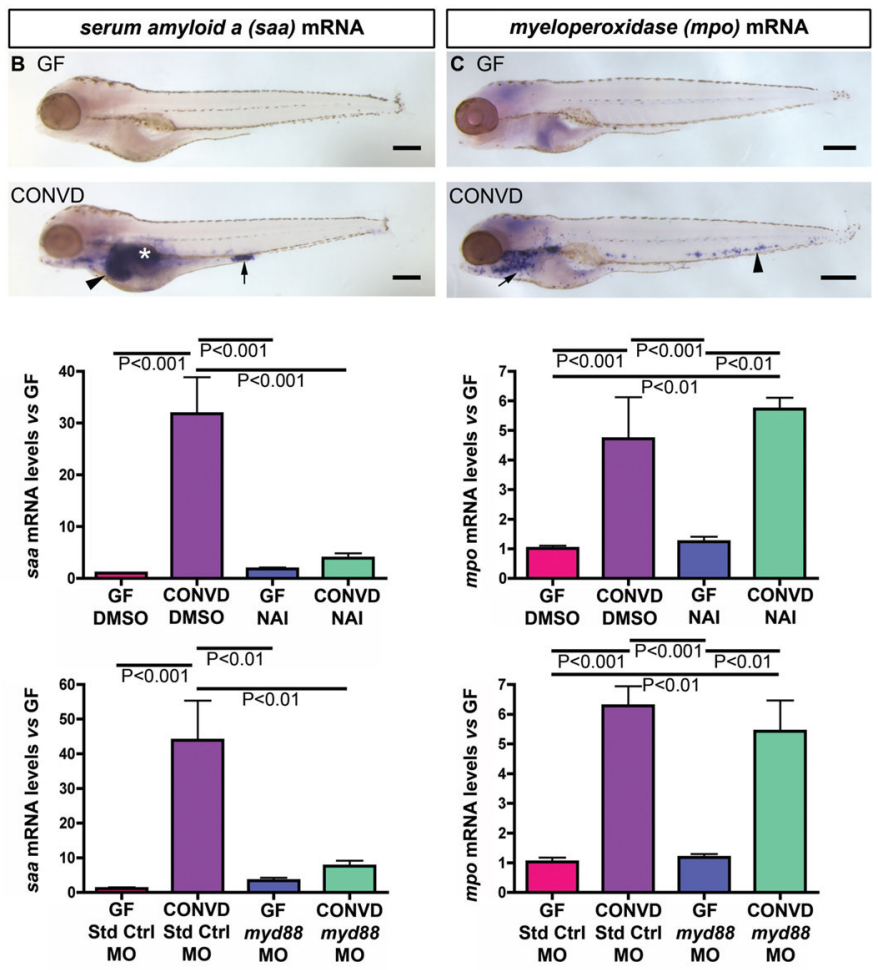

Fig. 6. Conventionalization of GF zebrafish stimulates NF-кB dependent immune responses in diverse cell types

(A-C) Semi-quantitative wholemount in situ hybridization of 6dpf GF and CONVD zebrafish using RNA probes for complement factor $b$ ( $c f b$ ), serum amyloid a (saa), and myeloperoxidase (mpo). (A) CONVD zebrafish show increased $c f b$ expression in the liver (black arrowhead) compared to GF controls. (B) CONVD zebrafish also display increased saa expression in liver (black arrowhead), swim bladder (white asterisk) and segment 3 of the intestine (black arrow) compared to GF controls. (C) CONVD larvae robustly express mpo in neutrophils in the caudal hematopoietic tissue (black arrowhead) and other locations (black arrow) compared to GF zebrafish. (D) qRT-PCR assays of whole 6dpf GF and CONVD zebrafish treated with DMSO vehicle from 3-6dpf shows that $c f b$, saa, and mpo are all significantly induced by the microbiota, and that treatment with 200nM NAI from 3$6 \mathrm{dpf}$ attenuates microbial induction of $c f b$ and $s a a$, but not mpo. (E) qRT-PCR assays of whole 6dpf GF and CONVD larvae injected at the 1-cell stage with either standard control morpholino (Std Ctrl MO) or a morpholino targeting myd88 (myd88 MO). qRT-PCR data in panels D-G are from biological duplicate pools (5-20 fish/pool) normalized to 18S rRNA levels and expressed as mean mRNA fold-difference \pm SEM. Scale bars: $200 \mu \mathrm{m}(\mathrm{A}-\mathrm{C})$. 

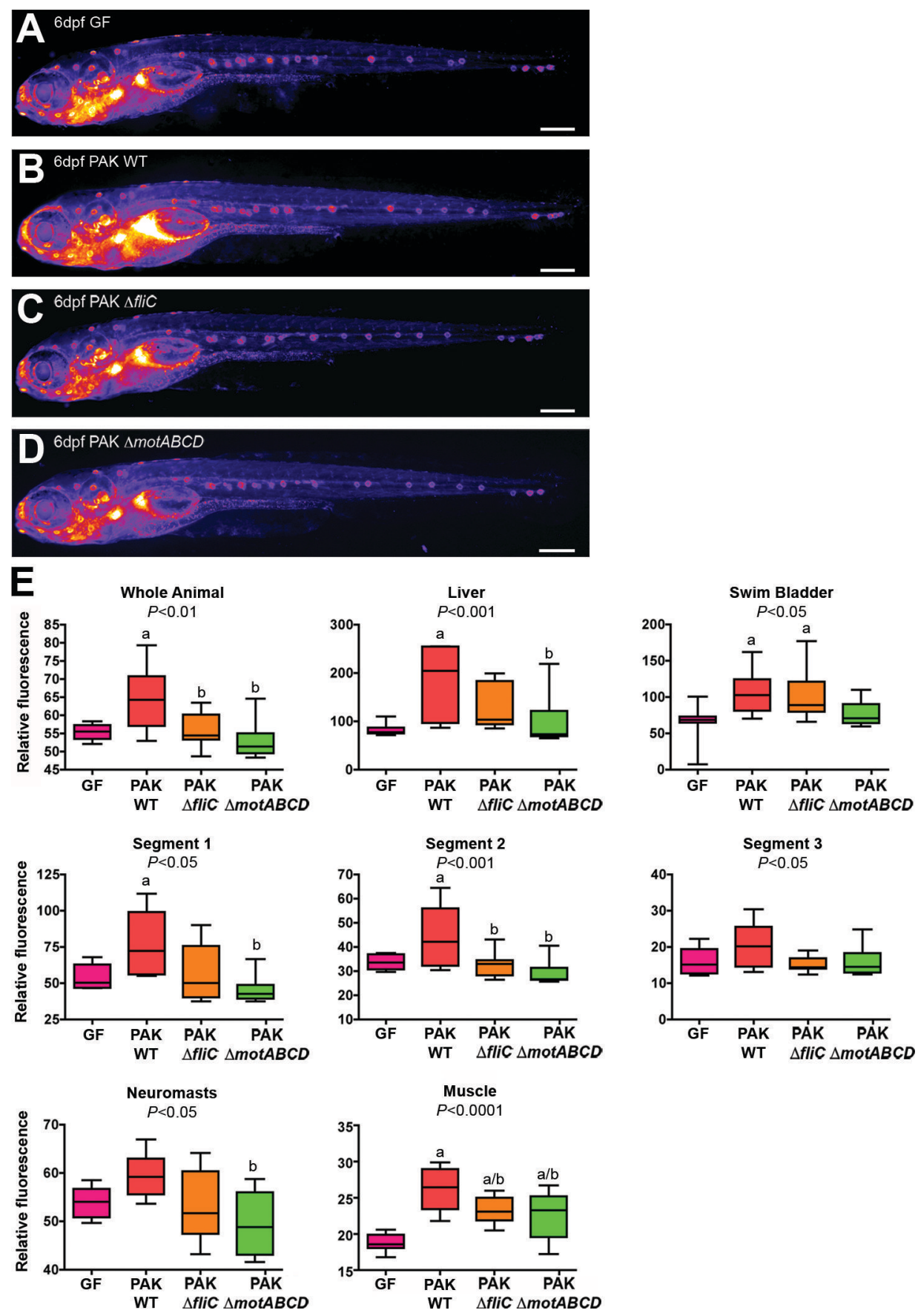

Fig. 7. P. aeruginosa flagellar function is required for NF-אB activation in gnotobiotic $\operatorname{Tg}($ NFkB:EGFP) zebrafish

Representative EGFP fluorescence heatmap images of 6dpf $T g(N F k B: E G F P)$ larvae raised GF (A), or mono-associated since $3 \mathrm{dpf}$ with wild type $P$. aeruginosa strain PAK (B) or deletion mutants PAK $\triangle f l i C(\mathrm{C})$ and $\triangle m o t A B C D(\mathrm{D})$. (E) Densitometric quantification of relative EGFP fluorescence for whole animal, liver, swim bladder, intestinal segments 1, 2, and 3, neuromasts, dorsal root ganglia (DRG), and muscle (10 fish/condition). One-way ANOVA P-values are shown in each panel, with significant differences (Tukey's post-test

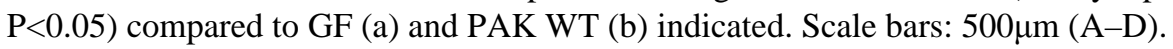

